\title{
SUSTAINABILITY OF REINFORCED CONCRETE FRAME STRUCTURES - A CASE STUDY
}

\author{
A. PUSKAS ${ }^{1} \&$ L. M. MOGA ${ }^{2}$ \\ ${ }^{1}$ Department of Structures, Technical University of Cluj-Napoca, Romania. \\ ${ }^{2}$ Department of Buildings and Management, Technical University of Cluj-Napoca, Romania.
}

\begin{abstract}
Traditionally, the engineering education is aiming to establish quantifiable, measurable units, and after that comparing those to utilise the unit considered more suitable. When thinking about sustainability of structures, traditional mentality has to be set aside, as comparing different structural systems is becoming a complex task. Choosing different materials for the same reinforced concrete structure has immediate comparable impact on the environment. Reinforced concrete structures are using excessively the limited limestone and other resources and, in the same time, a large quantity of energy for producing the rebar, the clinker and the structural concrete, having negative impact on the environment. Even if reinforced concrete structures are not generally known as the most sustainable solutions for several structural queries, reinforced concrete structural solutions are preferred for most of the situations due to the other advantages presented by these structures. Hence, considering that specific building indispensable for the society, the aim of obtaining sustainable buildings becomes equivalent to decrease their negative impact on the environment while still taking full advantage of their strength. This target can be achieved by judicious choose of the built-in materials. For a given multistorey reinforced concrete frame building, the scope is to establish the concrete and the reinforcing steel classes in such a way that the impact of these materials on the environment to be kept at the lowest possible level. This paper presents a study on an ordinary reinforced concrete frame structure designed using two different concrete classes (C16/20 and C30/37) and two different reinforcing bar classes (PC52 and S500), obtaining four different possibilities for the same solution. Different combinations of built-in materials are resulting different economic and environmental impacts. The environmental impact for the whole life cycle of the studied solutions, using different material qualities, is estimated using Athena Impact Estimator for Buildings, taking into consideration weighted life-cycle analysis indicators (total energy used, the quantity of solid emissions in air and water, the required natural resources consumed - especially the non-renewable ones - the impact owed to the depletion of the natural resources, human health and the impact on the ecosystems). Besides the environmental impact estimation, realisation cost is also evaluated for each structural solution, obtaining a relationship between the cost (as the major decision influencer) and the sustainability of the studied solutions.

Keywords: Structural sustainability, reinforced concrete sustainability, economy and sustainability, life-cycle analysis, material quality impact, case study.
\end{abstract}

\section{INTRODUCTION}

When thinking about structural design, engineers are used to focus on provisions of standards, limits imposed by codes and other generally valid formulas with respect to the material and structural behaviour, all those representing measurable quantities [1]. The essential requirements based on which structural design activities are performed are stated in the Council Directive 89/108/EEC [2]. The essential requirements to respect are (a) the mechanical resistance and stability, (b) safety in case of fire, (c) hygiene, health and environment, (d) safety in use, (e) protection against noise and (f) energy economy and heat retention [2]. Even if most of the requirements have been implemented, where necessary, into national or European design codes and norms, resulting principles, formulas, provisions and procedures easy to apply in the day-by-day design activity as well as quantifiable and measurable units as qualitative and quantitative markers of the design, others, like 'hygiene, health and environment' and 'energy economy', still suffer from lack of specific and practical measuring instruments. Worldwide concerns of specialists from the field of civil and environmental engineering 


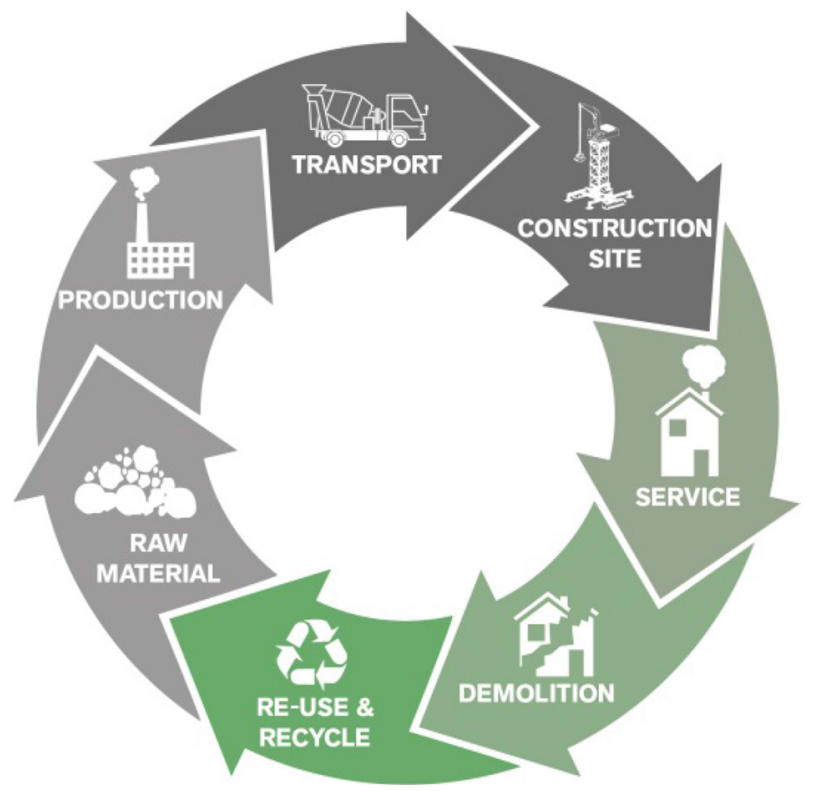

Figure 1: Desired life cycle of the construction materials.

in order to establish sustainable structural design methodologies could not remain without outcome. The ISO 14000 standard family on environmental management [3] provides tools to identify and control the environmental impact of companies and organisations and to improve their environmental performance [3], but their practical use in design and realisation of sustainable structures is almost negligible. One of the most efficient methodologies for obtaining a sustainable structural system is the impact assessment of the studied structure using life-cycle analysis (LCA), emphasised in studies performed by Danatzko and Sezen [4] and others. The LCA of structures is considering the impact of the whole cradle-to-grave and to cradle again circle of the materials, structures and buildings (Fig. 1), regulated by European framework standards EN 15643-1:2010 [5] and EN 15643-2:2011 [6].

Lack of statistical data for the whole life cycle of materials, structures and buildings with respect to their environmental impact (energy consumption including regenerable energy, especially the consumption of fossil fuels, quantity and quality of solid emissions to air and water, consumption of the necessary natural resources, especially of the non-renewable ones, the impact owed to the depletion of the natural resources, human health and the impact on the ecosystems) and the complexity of the realisation processes consists of the weakness of the method. In the same time the unfortunate mindset of investors to consider nothing but the realisation costs and revenues but also the lack of the specific education of specialists involved in the design, realisation, service, demolition and reuse of structures as well as of the legal- and clear standard obligations consists obstacle to destruct in the way of the desired consideration of the environment.

\section{SUSTAINABILITY OF STRUCTURES}

Sustainability by default lays on three pillars, which are not mutually exclusive but can be mutually reinforcing [7], representing nothing else than the reconciliation - or the compromise - of environmental, social equity and economic demands. When a need for a specific structure is formulated 


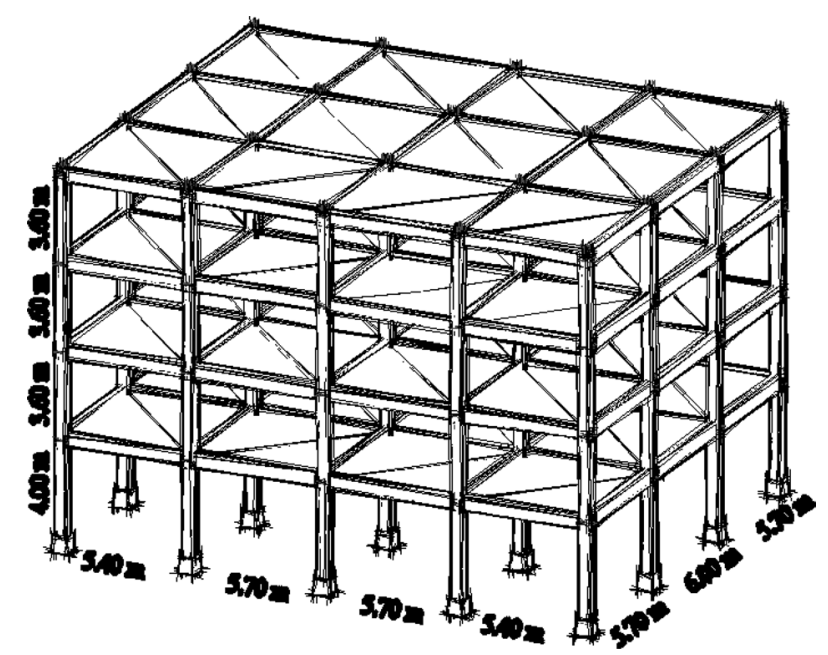

Figure 2: Typical reinforced concrete frame structure.

towards an engineer, there are well established and known methodologies - and traditions - for the economic impact assessments, while the environmental impact of the materials and structural systems used requires supplementary studies. As a consequence, the sustainability of a structure can be assessed only following the impact studies of the structure. Sustainability of a structure is influenced by the established static scheme, the type of the materials used, the ratios and quantities of the embedded materials, by the proposed realisation processes, the service period and eventual maintenance, and the possible recycling of the demolished structure. Studies performed by Puskas and Virag [8], Danatzko et al. [9] and others [10,11] are emphasising that in design phase the chosen structural systems have high influence on the sustainability of the whole project, but the embedded material qualities and quantities are having the largest influence on the sustainability of the structure. In case of reinforced concrete frame structure (Fig. 2), its sustainability depends on the material properties and quantities of the used structural concrete, being the building material used on the largest scale for the realisation of commercial, residential and industrial buildings.

Design principles based on the limit state concept used in conjunction with a partial factor method [12] are providing sufficient guidelines for realising reliable concrete structures, but if one intends to design sustainable concrete structures, supplementary guidelines and studies shall be necessary. Unfortunately, understanding the shortcoming of the structures responding to the same design theme realised in a less sustainable way is not equivalent to having at our disposal alternative structural solution with significantly less environmental impact.

\section{REINFORCED CONCRETE SUSTAINABILITY}

As building material reinforced concrete can be hardly considered a sustainable one in the rigorous sense of the word, but for large-scale buildings, its use cannot be avoided. At the same time, reinforced concrete, in its many forms, is a versatile building material that can provide many sustainable benefits by virtue of its economic construction, thermal mass, durability, fire resistance, acoustic performance, adaptability and recyclability. Choosing the appropriate method of concrete construction for the type of building will ensure that these benefits are combined to deliver the most 
sustainable outcome [13], having a perfect equilibrium between the economic, environmental and social impacts of the resulted building. Sustainability of reinforced concrete is determined by the sustainability of the used components.

\subsection{Concrete sustainability}

Concrete is the most used construction material on the world [14], obtained in concrete plants by mixing the constituents: aggregates, sand, cement, water, chemical and mineral admixtures. While some of the components can be obtained without high-energy consumption and without high quantity of waste production, the cement production, in the clinkering phase, requires high quantity of energy and large quantity of greenhouse gas is released.

For structural concrete replacement of up to $30 \%$ of the virgin aggregates with coarse recycledconcrete, aggregates can save important quantities of energy, with only slight reduction in the compressive strength of the concrete [15] and important recycled material quantity is re-used; if in the concrete mixing, grey water or rainwater is used, further reduction in the use of the natural resources can be achieved. Due to their valuable properties, the use of mineral admixtures (fly ash, silica fume, slag) in concrete is equivalent not only to saving important cement quantity from the mix but also to energy and greenhouse gas emission saving while industrial waste is reused [14]. In the cement production industry, there is a permanent competition between players to use as much as possible mineral admixtures to reduce the energy consumption to obtain not only a more sustainable cement but also a more cost-effective one, even with the risk of endangering its characteristics.

For the cement production, large quantities of limestone are used, threatening the limited limestone resources. The most energy-consuming stage is the heating of the limestone and clay mixture to high temperature (approximately $1450^{\circ} \mathrm{C}$ ) and then inter-grinding the resulting clinker with calcium sulphates and industrial by-products (such as blast furnace slag, limestone, natural pozzolana and industrial pozzolanic materials, e.g. fly ash, silica fume and burnt shale). Dry process state-of-the-art technologies requires $3.3 \div 3.6 \mathrm{GJ}$ of energy to produce a ton of clinker and then to grind it into cement, while wet process technologies requires approximately $56 \%$ to $66 \%$ more energy $[16,17]$.

\subsection{Reinforcement sustainability}

Reinforcing steel bars used for concrete structures are made of unfinished tempered steel, produced in hot rolled process with subsequent superficial hardening by heat treatment. To assure a better mechanical bond to the concrete, the structural reinforcements are ribbed. The ribs of the reinforcements are obtained by running the hot rolled smooth bars through rollers, deforming the bars to the ribbed shape.

While concrete is generally used for its compressive strength, the steel reinforcement is used to take over the tension appearing in the cross sections of concrete elements, having about 100 times higher tensile strength than the concrete, but with very similar thermal expansion coefficient. Inconveniencies appear due to its unprotected surface, which allows corrosion reaction even in ambient environmental conditions, and due to its low heat resistance. These inconveniences disappear when proper concrete cover is assured.

Reinforcing steel is a $100 \%$ recyclable material; it can be produced using $100 \%$ recycled scrap steel as feedstock. When a reinforced concrete structure arrives to the end of its life cycle, steel reinforcements separated from the concrete can be recycled and used again without quality loss, becoming prime material for reinforcing steel production. The embodied energy values and the necessary energy input per tonne of reinforcing steel are based on the energy used to melt and reform 
it, which, due to the high temperatures needed for melting, is comparable to the energy used for the clinker realisation, but being still less than half of the energy used for the melting and lamination of the structural steel [18]. Reinforcement production from scrap and recycled material can contribute to the EU requested $20 \%$ carbon emission reduction (by 2020, with respect to the level of 1990).

\section{CASE STUDY: DESIGN OF A MULTISTOREY FRAME STRUCTURE}

Frame structures are one of the simplest structural systems to use for multistorey buildings, having horizontal and vertical structural elements clearly defined, assuring functional flexibility and slenderness in the same time; their advantages are consisting also their limits, since their resistance to lateral forces is limited by their flexibility. Reinforced concrete multistorey frame structures are typical for apartment buildings.

\subsection{Description of the studied structure}

For the assessment of the impact on cost and embedded energy/environmental impact in case of different material qualities used for solving the same reinforced concrete frame structure, a model having four longitudinal and three transversal spans on four levels have been used. The longitudinal openings are 5.40, 5.70, 5.70 and $5.40 \mathrm{~m}$, respectively, whereas in the transversal direction the openings are 5.70, 6.00 and 5.70, respectively. The structure of the building is symmetric in plan. The heights of the levels are $4.00 \mathrm{~m}$ for the first level and $3.60 \mathrm{~m}$ for the others. The columns are assumed to be fixed at the base level (Fig. 2).

For the design of the permanent structure, variable and accidental load have been taken into account. Permanent loads are given by the own weight of the structure and the finishing on the floors, being considered $1.5 \mathrm{kN} / \mathrm{m}^{2}$ on the intermediate floors and $2.5 \mathrm{kN} / \mathrm{m}^{2}$ on the upper floor. On the perimeter beams, a uniform distributed load of $8.00 \mathrm{kN} / \mathrm{m}$ has been taken into account for the dead weight for the walls. Snow load on the roof has been taken as $1.60 \mathrm{kN} / \mathrm{m}^{2}$ on the upper floor and live loads of $2.50 \mathrm{kN} / \mathrm{m}^{2}$ on the intermediate floors, being increased with $0.80 \mathrm{kN} / \mathrm{m}^{2}$ for internal partitioning walls (as quasi-permanent loads). Wind loads have been evaluated taking into consideration wind basic velocity pressure of $0.50 \mathrm{kPa}$. Accidental loads given by seismic actions on the structure have been generated for region characterised by the upper limit of the period of the constant spectral acceleration branch $\mathrm{T}_{\mathrm{c}}=0.7 \mathrm{~s}$ and the design ground accelerations $\mathrm{a}_{\mathrm{g}}=0.16 \mathrm{~g}$, medium ductility class provisions being chosen to be fulfilled [19].

\subsection{Structural design: structural variations}

The presented structure has been calculated using the first-order linear-elastic analysis for the spatial model. In structural analysis, reduction in the elastic modulus has been considered according to seismic code P100 [20] and design code NP007 [21]: 0.5.E for seismic design situation, according to seismic code P100 [20], and 0.8 and 0.6.E for persistent and transient design situations established according to Eurocode [12], for columns and beams, respectively, according to NP 007-97 [21]. Four variants of structural solutions have been analysed for the given structure, given by combining concrete classes C16/20 and C30/37 and steel classes PC52 and S500 (Table 1).

Dimensions of the slab, beams and columns have been established taking into consideration the limit deflections established according to Eurocode [12] for load combinations in service ability limit states and for limit deflections according to seismic code P100 [20] in both ultimate and service ability limit states. Size differences appear due to the concrete class differences: the slab thickness is $14 \mathrm{~cm}$ for concrete class $\mathrm{C} 16 / 20$ and $13 \mathrm{~cm}$ for $\mathrm{C} 30 / 37$, transversal and longitudinal beam cross 
Table 1: Material quantities in the four variants.

\begin{tabular}{lcccc}
\hline Materiallvariant & Variant 1 & Variant 2 & Variant 3 & Variant 4 \\
\hline Concrete & C16/20 & C16/20 & C30/37 & C30/37 \\
Reinforcing steel & PC52 & S500 & PC52 & S500 \\
\hline
\end{tabular}

Table 2: Material quantities in the two situations.

\begin{tabular}{lrrrr}
\hline Elementlvariant & Variant 1 & Variant 2 & Variant 3 & Variant 4 \\
\hline Concrete $\left(\mathrm{m}^{3}\right)$ & & & \\
\hline Slab & 216.32 & 216.32 & 200.87 & 200.87 \\
Transversal beams & 62.64 & 62.64 & 52.20 & 52.20 \\
Longitudinal beams & 58.61 & 58.61 & 44.40 & 44.40 \\
Columns & 59.94 & 59.94 & 47.36 & 47.36 \\
\hline Reinforcement $(\mathrm{kg})$ & \multicolumn{5}{c}{} \\
\hline Slab & $19,062.39$ & $16,548.29$ & $22,687.72$ & $17,140.06$ \\
Transversal beams & $5,388.10$ & $4,558.80$ & $5,129.60$ & $4,147.10$ \\
Longitudinal beams & $5,183.28$ & $4,437.84$ & $4,966.88$ & $4,019.28$ \\
Columns & $12,301.80$ & $10,413.00$ & $7,013.60$ & $5,763.80$ \\
\hline
\end{tabular}

sections are $30 \times 60 \mathrm{~cm}$ for concrete class C16/20 and $25 \times 60 \mathrm{~cm}$ for $\mathrm{C} 30 / 37$, and $30 \times 55 \mathrm{~cm}$ and $25 \times 50 \mathrm{~cm}$, respectively. Column sizes of $45 \times 45 \mathrm{~cm}$ and $40 \times 40 \mathrm{~cm}$ have been chosen for the two concrete classes. Both structures have been designed for two situations of reinforcement quality used (PC52 and S500), resulting in considerable difference in the used quantities for the four variants. The resulting quantities are presented in Table 2.

\section{ENVIRONMENTAL IMPACT OF THE MATERIAL QUALITY}

Assessment of the environmental impact for the four studied solutions has been performed using a simplified procedure for the energy consumption of the embedded materials and a LCA of the structures realised using a life-cycle assessment software.

\subsection{Energy consumption calculation of the embedded materials using simplified procedure}

Comparison of the environmental impact of the used materials having different qualities is performed. In the simplified procedure, important differences in the necessary energy appear due to the concrete mix proportioning and to the quantity differences, but in the opposite sense. The quantities used for the realisation of $1 \mathrm{~m}^{3}$ of concrete and for the whole structure for the two concrete classes used (C16/20 and C30/37) are shown in Table 3.

Considering the energy consumption for cement production at $3.38 \mathrm{GJ} / \mathrm{t}$ (medium value for year 2006) [16], the necessary energy for the cement quantity corresponding to the calculated building is 558.3 GJ when using C16/20 concrete and 639.3 GJ when using C30/37 concrete. The necessary 
Table 3: Concrete mixture proportions and total quantities.

\begin{tabular}{lcclcc}
\hline & \multicolumn{2}{c}{$\mathrm{C} 16 / 20$} & & \multicolumn{2}{c}{$\mathrm{C30/37}$} \\
\cline { 2 - 3 } \cline { 6 - 7 } Constituentlconcrete class & $\begin{array}{c}\text { Unit quantity } \\
\left(\mathrm{kg} / \mathrm{m}^{3}\right)\end{array}$ & $\begin{array}{c}\text { Total quantity } \\
(\mathrm{kg})\end{array}$ & & $\begin{array}{c}\text { Unit quantity } \\
\left(\mathrm{kg} / \mathrm{m}^{3}\right)\end{array}$ & $\begin{array}{c}\text { Total quantity } \\
(\mathrm{kg})\end{array}$ \\
\hline Cement & 360.0 & $165,173.0$ & & 480.0 & $189,151.0$ \\
Sand, 0-4 mm & 690.0 & $316,581.0$ & & 660.0 & $260,083.0$ \\
Fine aggregate, 4-8 mm & 510.0 & $233,995.0$ & & 390.0 & $153,686.0$ \\
Coarse aggregate, 8-16 mm & 670.0 & $307,405.0$ & & 630.0 & $248,261.0$ \\
Water & 180.0 & $82,586.0$ & & 225.0 & $88,665.0$ \\
Chemical admixture & 2.5 & $1,156.0$ & & 5.0 & $1,970.0$ \\
\hline
\end{tabular}

Table 4: Necessary energy for the concrete production.

\begin{tabular}{lcccccc}
\hline & \multicolumn{2}{c}{$\mathrm{C} 16 / 20$} & & \multicolumn{2}{c}{$\mathrm{C} 30 / 37$} \\
\cline { 2 - 3 } \cline { 5 - 6 } & $\begin{array}{c}\text { For unit } \\
\text { quantity } \\
\text { Constituentlconcrete class }\end{array}$ & $\begin{array}{c}\text { Total quantity } \\
\left(\mathrm{GJ} / \mathrm{m}^{3}\right)\end{array}$ & & $\begin{array}{c}\text { For unit } \\
\text { quantity } \\
\left(\mathrm{GJ} / \mathrm{m}^{3}\right)\end{array}$ & $\begin{array}{c}\text { Total quantity } \\
(\mathrm{GJ})\end{array}$ \\
\hline Cement & 1.217 & & & & & \\
Sand, 0-4 mm & 0.062 & 28.3 & & 1.622 & 639.3 \\
Fine aggregate, 4-8 mm & 0.031 & 14.0 & & 0.059 & 23.4 \\
Coarse aggregate, 8-16 mm & 0.040 & 18.4 & & 0.023 & 9.2 \\
Water & - & - & & - & 14.9 \\
Chemical admixture & 0.002 & 1.1 & & 0.005 & - \\
\hline
\end{tabular}

Table 5: Necessary energy for the concrete production (GJ).

\begin{tabular}{lcccc}
\hline Material lvariant & Variant 1 & Variant 2 & Variant 3 & Variant 4 \\
\hline Energy for steel production & $1,069.36$ & 916.93 & $1,014.84$ & 792.29 \\
\hline
\end{tabular}

energy for the production of the concrete is presented in Table 4, where the necessary energy used for the concrete production has been considered as in [17]. The necessary energy for producing the complete quantity of concrete is $620.4 \mathrm{GJ}$ for the concrete class C16/20 (variants 1 and 2) and 688.7 GJ for the class C30/37 (variants 3 and 4).

If the energy intensity value is taken as $25.5 \mathrm{GJ} / \mathrm{t}$ according to Worldsteel [22] as the mean value for blast furnace - basic oxygen furnace production route, the necessary energy for the production of the whole reinforcement quantity for the four variants are presented in Table 5.

If the main criterion for the comparison of the sustainability of the studied structural variants is the total energy consumption for the production of the main materials (concrete and steel), the necessary energy for each structural variant is presented in Table 6. 
Table 6: Necessary energy for the main material production (GJ).

\begin{tabular}{lcccc}
\hline Materiallvariant & Variant 1 & Variant 2 & Variant 3 & Variant 4 \\
\hline Energy for material production & $1,689.72$ & $1,537.29$ & $1,703.57$ & $1,481.02$ \\
\hline
\end{tabular}

- Total Energy Consumption [MJ]

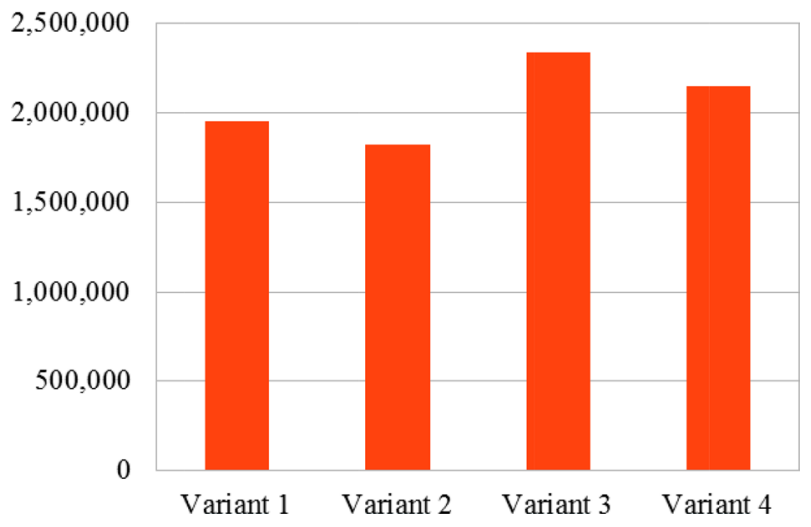

Figure 3: Total energy consumption for the structural variants.

\subsection{Life-cycle analysis of the embedded materials using assessment software}

The environmental impact of the embedded materials has been assessed using Athena Impact Estimator for Buildings life-cycle assessment software. For the analysis of the structural impact in normal service conditions, the building life expectancy does not have any influence nor does the replacement influence the analysis. Taking into consideration the material quantities presented earlier for the studied four variants, the total energy consumption resulted by the life-cycle assessment is presented in Fig. 3. The total primary energy consumption includes the necessary energy for the whole life cycle of the proposed structure, including manufacturing, construction, maintenance, endof-life and operating energy, composed by hydro, coal, diesel, feedstock, heavy fuel oil, LPG, natural gas and nuclear energy [23]. Comparison of the fossil fuel consumption for the studied variants is shown in Fig. 4. The comparison is obtained using the LCA software.

\section{COST IMPACT ESTIMATION FOR THE STRUCTURAL VARIANTS}

Considering market prices for material and labour costs, the realisation cost of the four structural variants have been estimated. Table 7 presents the total cost for variants 1 and 2, whereas Table 8 presents the cost of the structural variants 3 and 4 .

Important price difference appears due to the reinforcement quality; even if the use of higher concrete class results a higher concrete cost, the economy resulting from using a higher grade reinforcing steel is of greater value than the price difference resulting from the concrete class increasing. It is important to remark that the site location is highly influencing the realisation cost: while transportation cost of the reinforcement is representing a reduced percentage of the total cost, in the case 


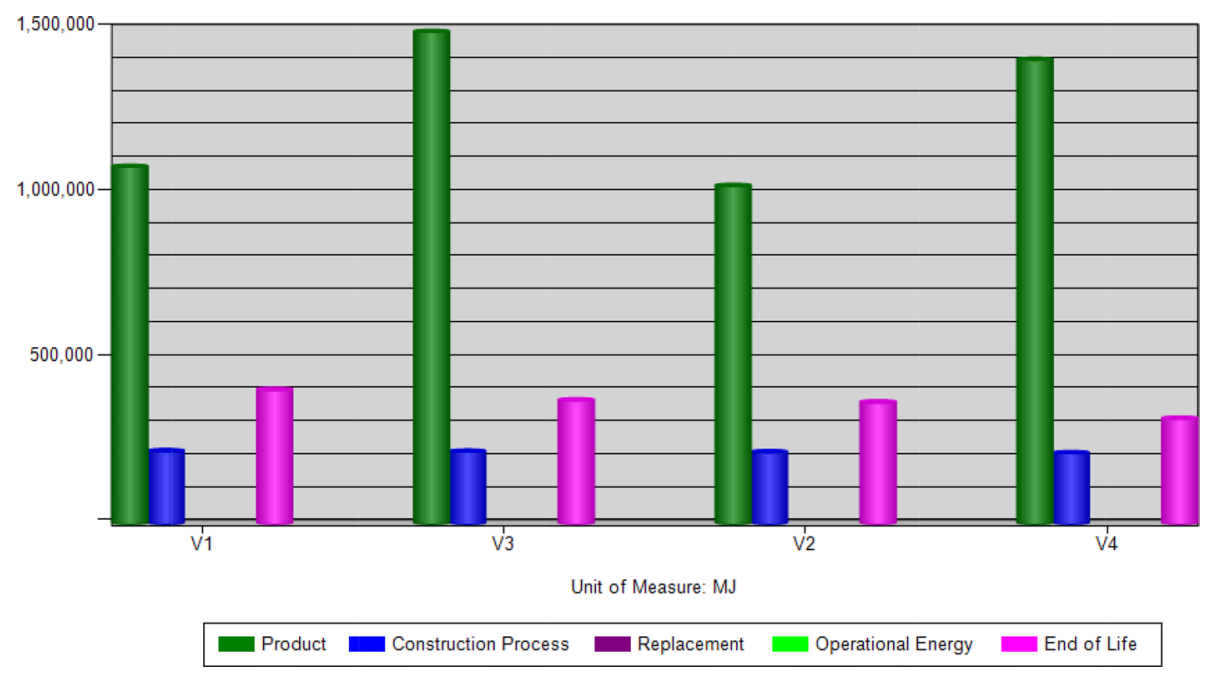

Figure 4: Comparison of the fossil fuel consumption for the structural variants.

Table 7: Total cost for structure realisation - variants 1 and 2.

\begin{tabular}{|c|c|c|c|c|c|}
\hline & $\begin{array}{l}\text { Quantity, } \\
\text { Var. 1 }\end{array}$ & $\begin{array}{l}\text { Quantity, } \\
\text { Var. } 2\end{array}$ & U.P. $(€)$ & $\begin{array}{l}\text { Total price, } \\
\text { Var. } 1(€)\end{array}$ & $\begin{array}{l}\text { Total price, } \\
\text { Var. } 2(€)\end{array}$ \\
\hline $\begin{array}{l}\text { Concrete for slabs and } \\
\text { beams }\left(\mathrm{m}^{3}\right)\end{array}$ & 337.6 & 337.6 & 63.37 & $21,392.7$ & $21,392.7$ \\
\hline Concrete for columns $\left(\mathrm{m}^{3}\right)$ & 59.9 & 59.9 & 63.37 & $3,798.6$ & $3,798.6$ \\
\hline $\begin{array}{l}\text { Rebars for slabs and } \\
\text { beams }(\mathrm{kg})\end{array}$ & $29,633.8$ & $25,544.9$ & 0.93 & $27,489.5$ & $23,696.5$ \\
\hline Rebars for columns (kg) & $12,301.8$ & $10,413.0$ & 0.93 & $11,411.7$ & $9,659.5$ \\
\hline $\begin{array}{l}\text { Formwork for slabs and } \\
\text { beams }\left(\mathrm{m}^{2}\right)\end{array}$ & $2,200.9$ & $2,200.9$ & 11.50 & $25,310.3$ & $25,310.3$ \\
\hline Formwork for columns $\left(\mathrm{m}^{2}\right)$ & 512.6 & 512.6 & 13.30 & $6,818.1$ & $6,818.1$ \\
\hline Total cost & & & & $96,220.8$ & $90,675.7$ \\
\hline
\end{tabular}

of the concrete the site location has huge influence on the concrete and on the cost of the concrete components.

\section{DISCUSSION}

As shown previously, the sustainability of a reinforced concrete structure is determined by the sustainability of the used components and their ratio. The present study refers to a structurally simple but realistic reinforced concrete building; similar structures are often used for multistorey commercial or residential buildings. The comparison of the structures has been limited to the realisation cost of the structures and to the necessary energy used for producing the total concrete and reinforcement quantity and the total primary energy necessary for the life cycle of the structure, respectively. 
Table 8: Total cost for structure realisation - variants 3 and 4 .

\begin{tabular}{|c|c|c|c|c|c|}
\hline & $\begin{array}{l}\text { Quantity, } \\
\text { Var. } 3\end{array}$ & $\begin{array}{l}\text { Quantity, } \\
\text { Var. } 4\end{array}$ & U.P. $(€)$ & $\begin{array}{l}\text { Total price, } \\
\text { Var. } 3(€)\end{array}$ & $\begin{array}{l}\text { Total price, } \\
\text { Var. } 4(€)\end{array}$ \\
\hline $\begin{array}{l}\text { Concrete for slabs and } \\
\text { beams }\left(\mathrm{m}^{3}\right)\end{array}$ & 297.5 & 297.5 & 78.83 & $23,450.2$ & $23,450.2$ \\
\hline Concrete for columns $\left(\mathrm{m}^{3}\right)$ & 47.4 & 47.4 & 78.83 & $3,733.5$ & $3,733.5$ \\
\hline $\begin{array}{l}\text { Rebars for slabs and } \\
\text { beams }(\mathrm{kg})\end{array}$ & $32,784.2$ & $25,306.4$ & 0.93 & $30,412.0$ & $23,475.3$ \\
\hline Rebars for columns (kg) & $7,013.6$ & $5,763.8$ & 0.93 & $6,506.1$ & $5,346.7$ \\
\hline $\begin{array}{l}\text { Formwork for slabs and } \\
\text { beams }\left(\mathrm{m}^{2}\right)\end{array}$ & $2,176.3$ & $2,176.3$ & 11.50 & $25,027.1$ & $25,027.1$ \\
\hline Formwork for columns $\left(\mathrm{m}^{2}\right)$ & 457.0 & 457.0 & 13.30 & $6,077.6$ & $6,077.6$ \\
\hline Total cost & & & & $95,206.5$ & $87,110.4$ \\
\hline
\end{tabular}

When calculating only with the simplified method, the necessary energy consumption for the production of the concrete and reinforcing steel economy on the energy due to the concrete quantity reduction due to the use of higher class concrete seemed to be sufficient to compensate the impact of the concrete class increase. When calculating the total necessary primary energy for the life cycle of the studied variants, the influence of the concrete class increase seems to be more important than the economy due to quantity increased. The influence on the sustainability improvement of the complete structure due to the reinforcing steel grade increase is indisputable and confirmed by both calculation methods, but in the case of the concrete differences appear between the results. In the simplified calculations, the overall most sustainable structural solution is Variant 4, the other solutions use $15.2 \%$ (Variant 1), $4.3 \%$ (Variant 2) and 16\% (Variant 3) more energy for the concrete and reinforcing steel production. Using the life-cycle assessment software, the most sustainable structural solution seems to be Variant 2, the other solutions use 7.1\% (Variant 1), 22\% (Variant 3) and $15 \%$ (Variant 4) more primary energy for the complete life cycle of the structural solutions.

From the cost point view, the use of superior material quality for concrete leads to a price increase of $7.9 \%$; this increase is tempered by the price decrease resulted from the use of high-grade reinforcing steel, resulting in a final cost difference compared with Variant 4 of $10.5 \%$ for Variant $1,4.1 \%$ for Variant 2 and $9.3 \%$ for Variant 3. In the same time, concrete quantity decrease leads to a decreased total weight of the structure, which can lead to further advantages. The use of superior quality ribbed reinforcement compared with the lower quality reinforcing bars leads to an economy of over $15 \%$.

\section{CONCLUSIONS}

Properly designed reinforced concrete structures can be considered sustainable solutions if according to the proposed impact criteria their performance is admissible. In the assessment of the structural solutions, the most important assessment criterion has to be specified prior to the assessment start. The studied solutions presented are emphasising the influence on the sustainability and on the cost of the structures: the use of superior quality reinforcing steel is leading to less energy consumption and lower overall cost, the use of higher grade reinforcing steel is being recommended against lower grade steel due to the indicated advantages. In case of concrete, results are not convincing; from economy point of view, higher class concrete can be considered more favourable, but the environmental impact 
of the concrete depends on the chosen assessment method. More detailed study on the structures to obtain a more sustainable structural solution might be necessary, but it has to be remarked that results are depending on the specific site location.

Due to the large amount of embedded energy, resource used and waste produced sustainability of structural solutions cannot be neglected, but proper measurement of the structural sustainability requires further developments of the assessment methods.

\section{REFERENCES}

[1] Puskas, A. \& Moga, L.M., Sustainability of building Relationship between economy and sustainability for a multi-storey reinforced concrete frame structure. WIT Transactions on Ecology and the Environment, Vol. 176, WIT Press: Southampton, 2013, ISSN 1743-3541, doi: 10.2495/ESUS130171.

[2] Council Directive 89/108/EEC, http://eur-lex.europa.eu/

[3] ISO 14000 standard family, http://www.iso.org/iso/home/standards/management-standards/ iso14000.htm doi: http://dx.doi.org/10.1002/0470090782.app1

[4] Danatzko, J.M. \& Sezen, H., Sustainable structural design methodologies. Practice Periodical on Structural Design and Construction, 16(4), pp. 186-190, 2011, ISSN 1943-5576, doi: 10.1061/(ASCE)SC.1943-5576.0000095. doi: http://dx.doi.org/10.1061/(asce)sc.1943$\underline{5576.0000095}$

[5] Sustainability of construction works - Sustainability assessment of buildings - Part 1: General framework, EN 15643-1:2010, European Committee for Standardization (CEN), http://www. cen.eu

[6] Sustainability of construction works - Assessment of buildings - Part 2: Framework for the assessment of environmental performance, EN 15643-2:2011, European Committee for Standardization (CEN), http://www.cen.eu

[7] United Nations General Assembly, 2005 World Summit Outcome, Resolution A/60/1, adopted by the General Assembly on 15 September 2005.

[8] Puskas, A. \& Virag, J., Cost or energy efficiency? Criteria in design of a reinforced concrete structure of a public building. Proc. of the 8th Int. Conf. on Energy \& Environment, eds. V. Mladenov, T. Tashev, H. Wang, I. Kralov, S. Stankevich, P. Yildiz \& J. Burley, Rhodes Island, pp. 112-117, ISBN: 978-960-474-312-4.

[9] Danatzko, J., Sezen, H. \& Chen, Q., Sustainable design and energy consumption analysis for structural components. Journal of Green Building, Winter 2013, 8(1), pp. 120-135. doi: 10.3992/jgb.8.1.120. doi: http://dx.doi.org/10.3992/jgb.8.1.120

[10] Vazquez, E., Rola, S., Martins, D., Alves, L., Freitas, M. \& Pinguelli Rosa, L., Sustainability in Civil Construction: Application of an Environmental Certification Process (LEED) During the Construction Phase of a Hospital Enterprise - Rio De Janeiro/Brazil. International Journal of Sustainable Development and Planning, 8(1), pp. 1-19, 2013, ISSN: 1743-761X, doi: 10.2495/SDP-V8-N1-1-19. doi: http://dx.doi.org/10.2495/sdp-v8-n1-1-19

[11] Mwasha, A., Williams, R.G. \& Iwaro, J., Significance of sub-criteria in measuring sustainable performance of building envelope development. International Journal of Sustainable Development and Planning, 8(4), pp. 464-484, 2013, ISSN: 1743-761X, doi: 10.2495/SDP-V8N4-464-484. doi: http://dx.doi.org/10.2495/sdp-v8-n4-464-484

[12] Eurocode - Basis of structural design, EN 1990/1992. doi: http://dx.doi.org/10.3403/03202162

[13] Cement Concrete \& Aggregates Australia, Sustainable Concrete Buildings, Briefing, 13 April 2010. 
[14] Naik, T.R., Sustainability of concrete construction, CBU-2007-02, ASCE Practice Periodical on Structural Design and Construction, 13(2), pp. 98-103, 2008. doi: http://dx.doi. org/10.1061/(asce)1084-0680(2008)13:2(98)

[15] Corinaldesi, V., Structural concrete prepared with coarse recycled concrete aggregate: from investigation to design. Advances in Civil Engineering, Hindawi Publishing Corporation, 2011. doi: http://dx.doi.org/10.1155/2011/283984

[16] Cochez, E., Nijs, W., Simbolotti, G. \& Tosato, G., Cement production. IEA ETSAP - Technology Brief I03 - June 2010: IEA ETSAP - Energy Technology Systems Analysis Programme.

[17] Struble, L. \& Godfrey, J., How sustainable is concrete? Proc. of the International Workshop on Sustainable Development and Concrete Technology, ed. K. Wang, Iowa State University, pp. 201-212, 2004.

[18] Sustainable concrete, http://www.sustainableconcrete.org.uk

[19] Puskas, A. \& Sandor, G.A., Comparative study of a reinforced concrete structure for high and medium ductility, Treci International Naucho-Strucni Skup GNP 2010, pp. 529-534, 2010.

[20] P100-1/2006, Earthquake resistance design code - Part I - General design rules for buildings, 2006. doi: http://dx.doi.org/10.3403/00752563

[21] NP 007-97, Design code for reinforced concrete structures, 1997.

[22] Worldsteel, http://www.worldsteel.org

[23] Athena Impact Estimator for Buildings 4.5, Athena Sustainable Materials Institute, http:// www.athenasmi.org 